\author{
How to cite this article: \\ Author: Jerzy Bochnia \\ Title of article: „The use of 3D scanning in reverse engineering” \\ Mechanik, No. 3 (2019) \\ DOI: https://doi.org/10.17814/mechanik.2019.3.27
}

\title{
The use of 3D scanning in reverse engineering
}

\section{JERZY BOCHNIA*}

* Dr inż. Jerzy Bochnia, jbochnia@tu.kielce.pl, https://orcid.org/0000-0001-7540-3822 - Politechnika Świętokrzyska, Kielce, Polska

The procedure of building a surface model and inspecting its dimensions by scanning a real object is discussed. The body of a two-part master cylinder was scanned. Geometrical dimensions of the obtained surface model were inspected. Based on obtained data, a 3D CAD model of the scanned object was developed.

KEYWORDS: reverse engineering, 3D scanner, surface model, dimensional inspection

\section{Introduction}

Reverse engineering was born before the introduction of modern computer-aided techniques. Using conventional measurement methods, data was obtained that allowed the production documentation of the object to be prepared. Only the appearance of coordinate measuring machines allowed the collection of a large number of 3D points enabling the shape of an object to be reproduced with a certain accuracy.

The milestone in the development of scanning techniques was the construction of laser and optical scanners collecting point clouds, as well as 3D software for processing measurement data necessary to create a virtual object model [1, 2].

Modern optical scanners record up to 2 million points during a single measurement lasting about a second. Appropriate processing allows for full analysis of the measurement - i.e. dimensioning of the object, comparison with CAD data, preparation of a deviation map and inspection of cross-sections. Results of comparative tests of various scanners are presented in [2].

The use of optical scanners in various sectors of economy is growing, especially in industry, e.g. in the automotive industry [3] or reverse engineering, for object design based on the obtained point cloud, and in measurements $[4,5]$, for assessing the quality of products by comparing with CAD documentation and assessment of wear of components after various periods of operation, e.g. wear of tools [6-9]. Comparative research is also carried out on various methods of creating a point cloud, e.g. contact methods using coordinate measuring machines, scanners and computer tomographs [10].

\section{Scanning methodology}

The body of the dual-section master cylinder was chosen as the scan object. This is an example of an element from the automotive industry.

Often, spare parts need to be made in the absence of production documentation. Such documentation can be reproduced by reverse engineering.

Fig. 1 shows the procedure for scanning and building the pump surface model and geometry inspection, the knowledge of which is necessary to build a solid CAD model.

Scanning was performed with a 3D GOM Atos II Triple Scan [10] (fig. 2). Two cameras of the device record the course of fringes moving on the surface of the scanned object; the scanner software calculates point coordinates for each camera pixel. The scanner allows to record up to 1.4 million points during a single measurement. The advantage of discretization with a scanner is the possibility of any positioning of the object in the field of view of the device, which is helped by a computer-controlled rotary table. 


\section{Start}

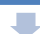

Selection of the object to be scanned: two-section master cylinder

$\checkmark$

Placing markers (reference points) on the scanned item

$\checkmark$

Placing the object on the rotary table of the Atos II scanner;

setting the scanning steps, light intensity and camera tilt angles

$\checkmark$

Six-position scanning, gluing the point cloud and cleaning the received scan

$\checkmark$

Scan polygonization, repair of triangle mesh discontinuities

प.

\section{Ready surface model}

$r$

Inspection of geometrical dimensions and deviations of the shape of the surface model

$\checkmark$

Analysis of measurement results

\section{End}

Fig. 1. Procedure of building a surface model and inspecting its dimensions on the basis of scanning a real object

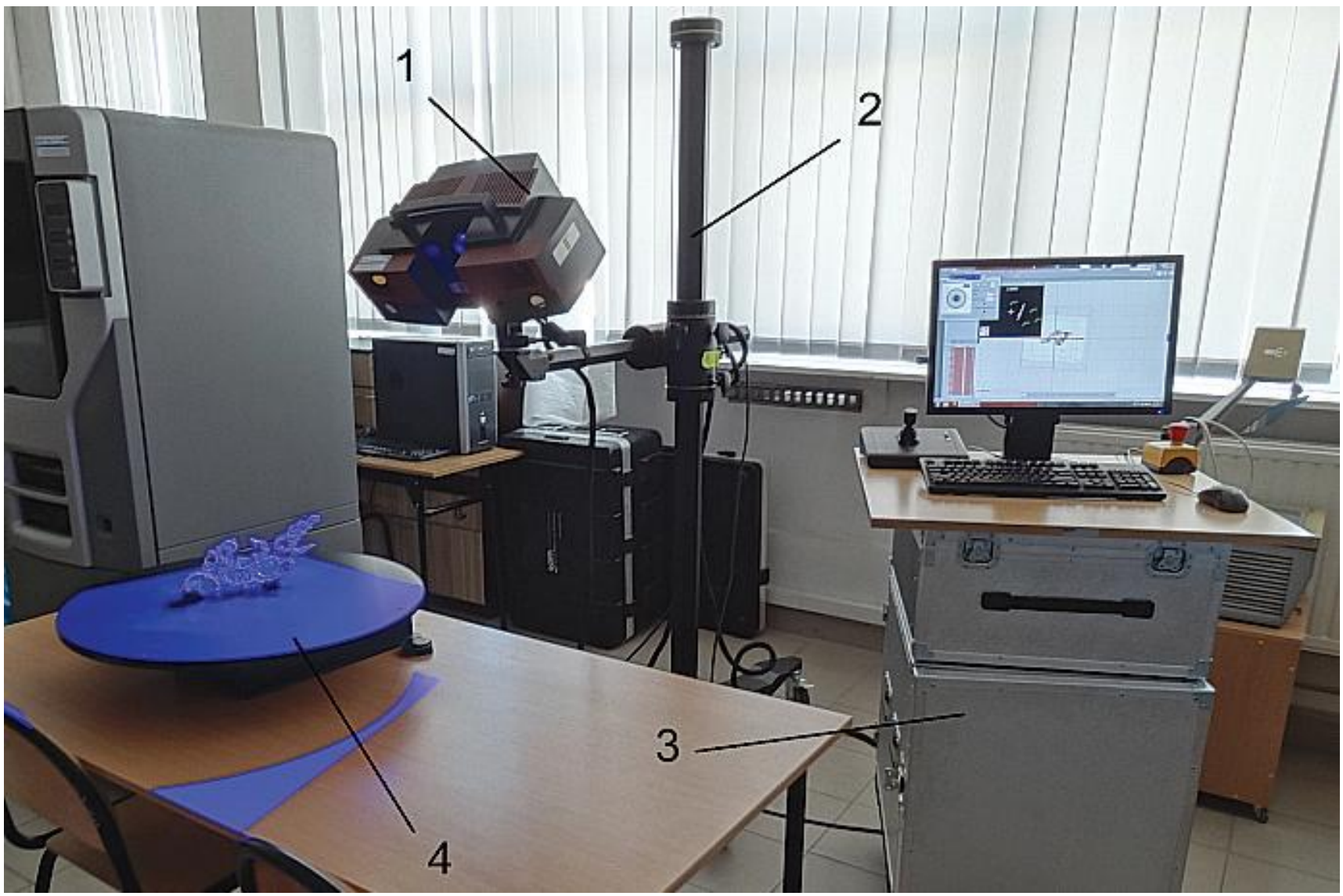

Fig. 2. Research stand in the Reverse Engineering Laboratory of the Department of Mechanical Technology and Metrology at the Kielce University of Technology; 1 - Atos II scanner, 2 - tripod, 3 - computer unit for data acquisition and scanner and rotary table control, 4 - rotary measuring table 
The scanner head is positioned manually or automatically. After measuring, the head or scanned item is moved to measure areas that were not scanned in the previous setting. All measurements are automatically transformed into a common coordinate system and generate a 3D point cloud.

Technical data of the GOM Atos II Triple Scan scanner:

- camera resolution: $2 \times 5,000,000$ pixels,

- measuring area: from $28 \times 29$ to $2000 \times 1500 \mathrm{~mm}^{2}$,

- density of measured points: $0.02 \div 0.79 \mathrm{~mm}$,

- recording of measured points: up to 1,400,000,

- working distance: $490 \div 2000 \mathrm{~mm}$,

- working temperature: $5 \div 40^{\circ} \mathrm{C}$ (without condensation),

- rotary table,

- maximum permissible error $\pm 0.01 \mathrm{~mm}, \pm 0.03 \mathrm{~mm}$ for different scanning ranges.

\section{Scanning results}

The pump was scanned in six positions (fig. 3 - position No. 1).

Eighteen scanning steps were defined, which provided a $20^{\circ}$ rotation angle for one scan (fig. $4 \mathrm{a}$ ). There are reference points (markers) on the surface of the scanned object, which allow "gluing" of point clouds obtained during digitization in individual positions. The intensity of light generated by the scanner was set to ensure the quality of the process. The individual scan phases can be observed on the computer monitor (fig. 4).

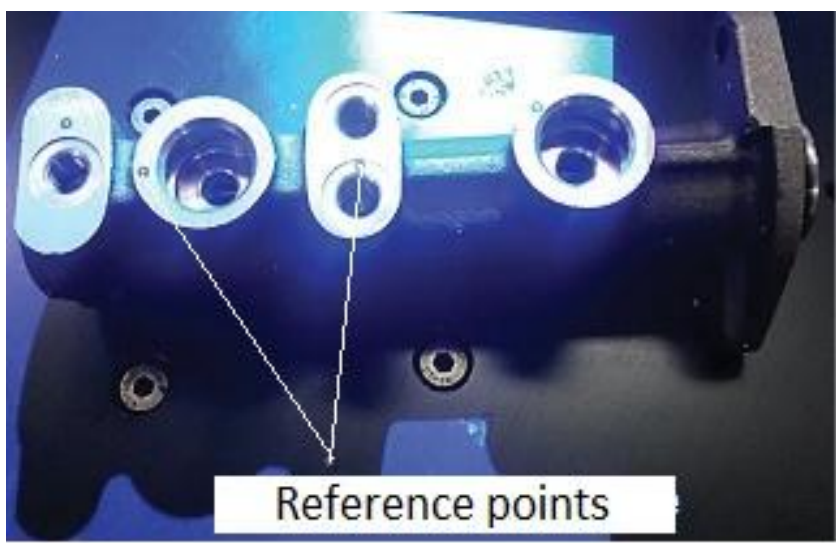

Fig. 3. Position No. 1 of the item placed on the scanner's rotary table

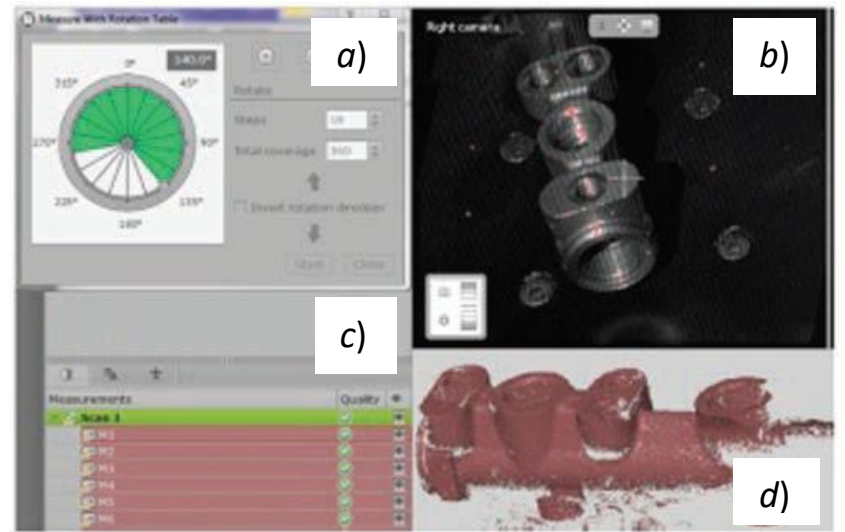

Fig. 4. The course of object scanning using the GOM Inspect program for position No. 1: $a$ ) scanning step setting panel, $b$ ) camera preview (lighting intensity setting panel), $c$ ) scanning quality control, d) point cloud obtained after a single step scan

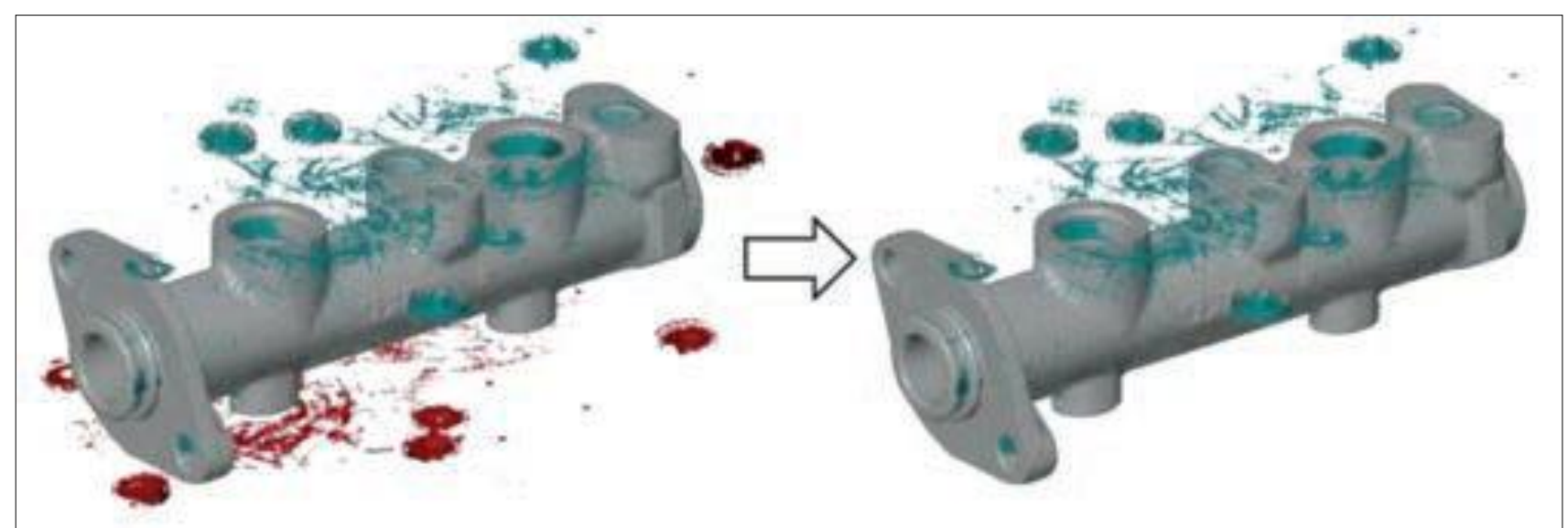

Fig. 5. Scanned item in the process of removing unnecessary points using the GOM Inspect program 


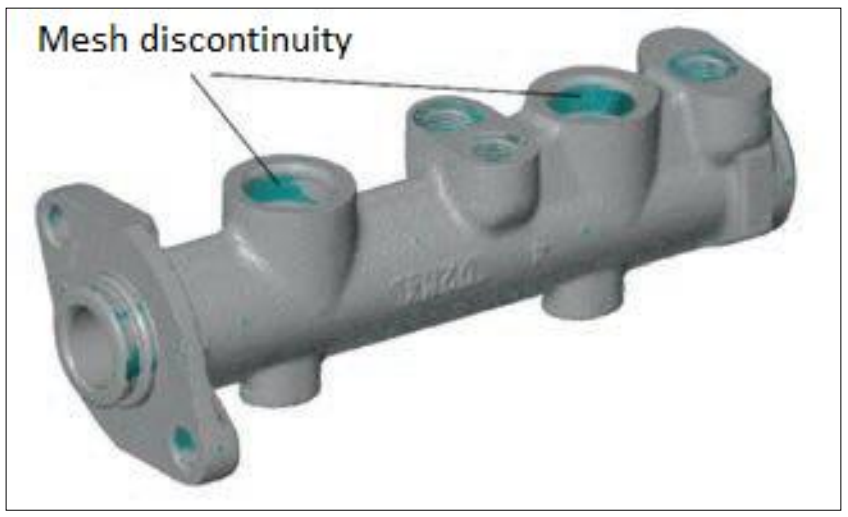

Fig. 6. Scanned item after cleaning

Fig. 7. Replacement of a point cloud with a surface model in the form of a triangle mesh [12]

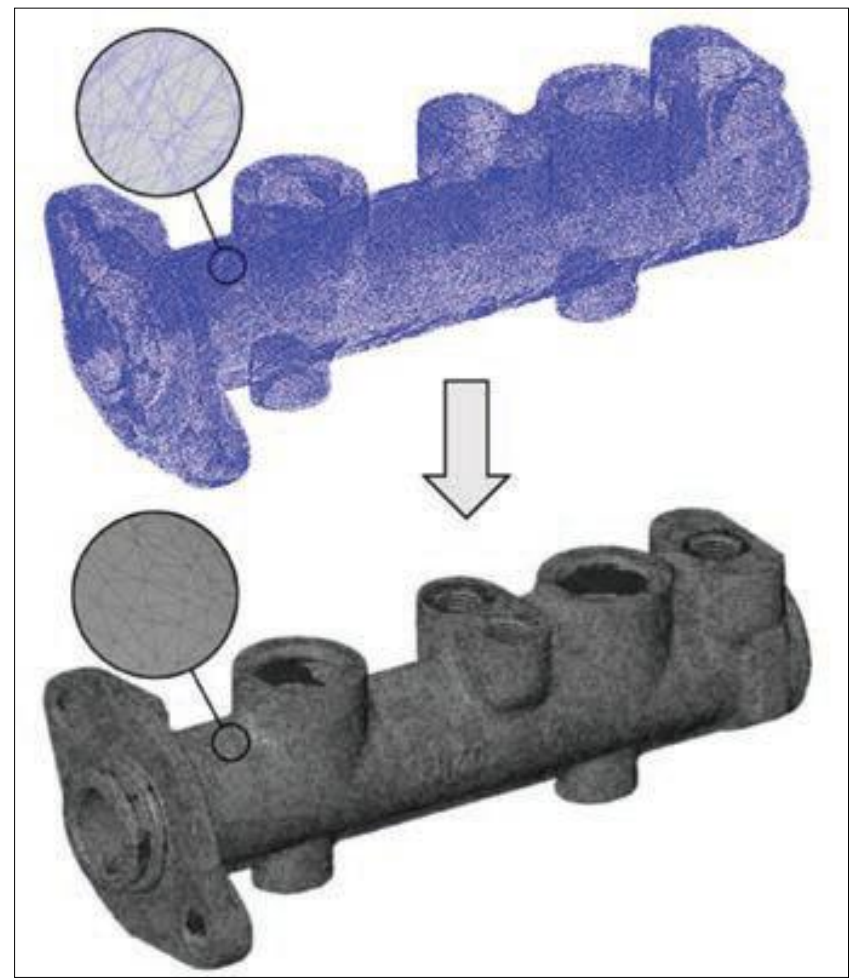

Fig. 5 shows the point cloud obtained after joining the clouds from all six positions in the process of removing unwanted elements (so-called garbage). Fig. 6 shows the scanned object after cleaning, prepared for polygonization, and fig. 7 - polygonization.

The last stage of building the surface model mesh is removing discontinuities (so-called holes). Fig. 8 shows the hole removal by the method of creating "bridges" used for larger discontinuities, while fig. 9 - ready surface model of the scanned pump.

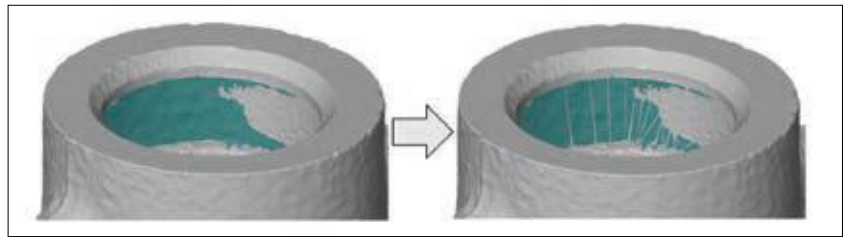

Fig. 8. Creating "bridges" of the surface model mesh to close discontinuities (holes)

Fig. 9. Finished surface model after scanning, cleaning and removing the discontinuities of the triangle mesh [12]

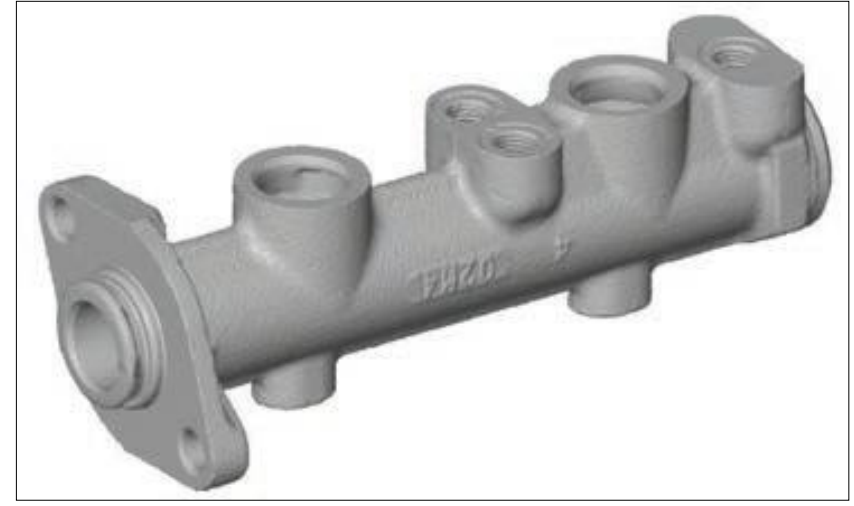

Only the finished surface model can be inspected for dimensions. Measurement of the geometry of the obtained scan consists in matching simple geometric elements, such as: point, segment, circle or cylinder, to the obtained shape and determining their dimensions.

Ten inspections were carried out. Sample results are shown in figs. 10 and 11. In contrast, fig. 12 shows sample results of shape deviation measurements.

Based on the measurements and analysis of the results, one can draw a solid model of the scanned item in the CAD 3D program, and then use this model in further operations, e.g. to develop a technological process using the CAM program or to develop a sketch of a 2D part as a reconstruction of the executive documentation - as in the case of the pump presented in [12]. 


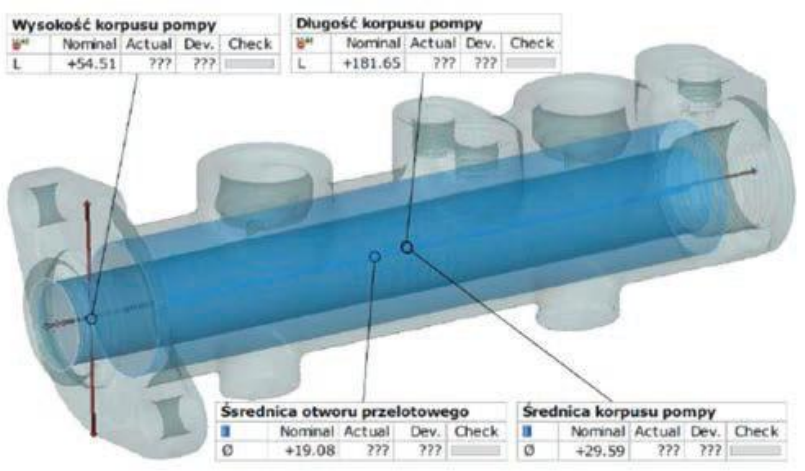

Fig. 10. Inspection results of the dimensions of the scanned item

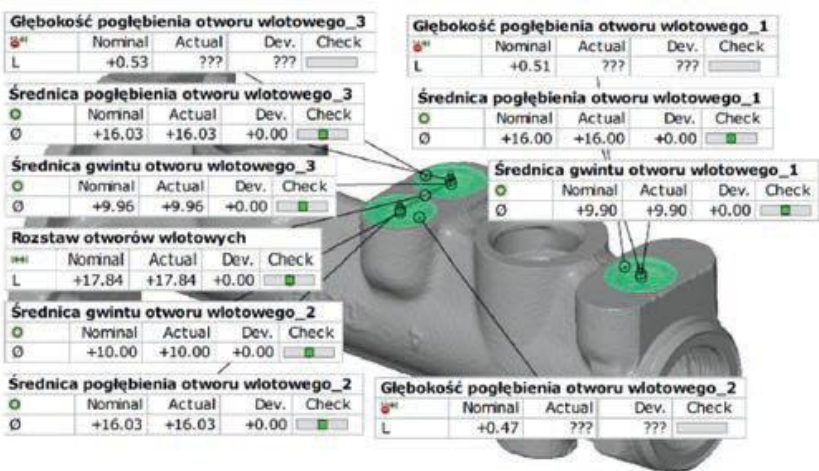

Fig. 11. Inspection results of the inlet holes dimensions of the scanned pump

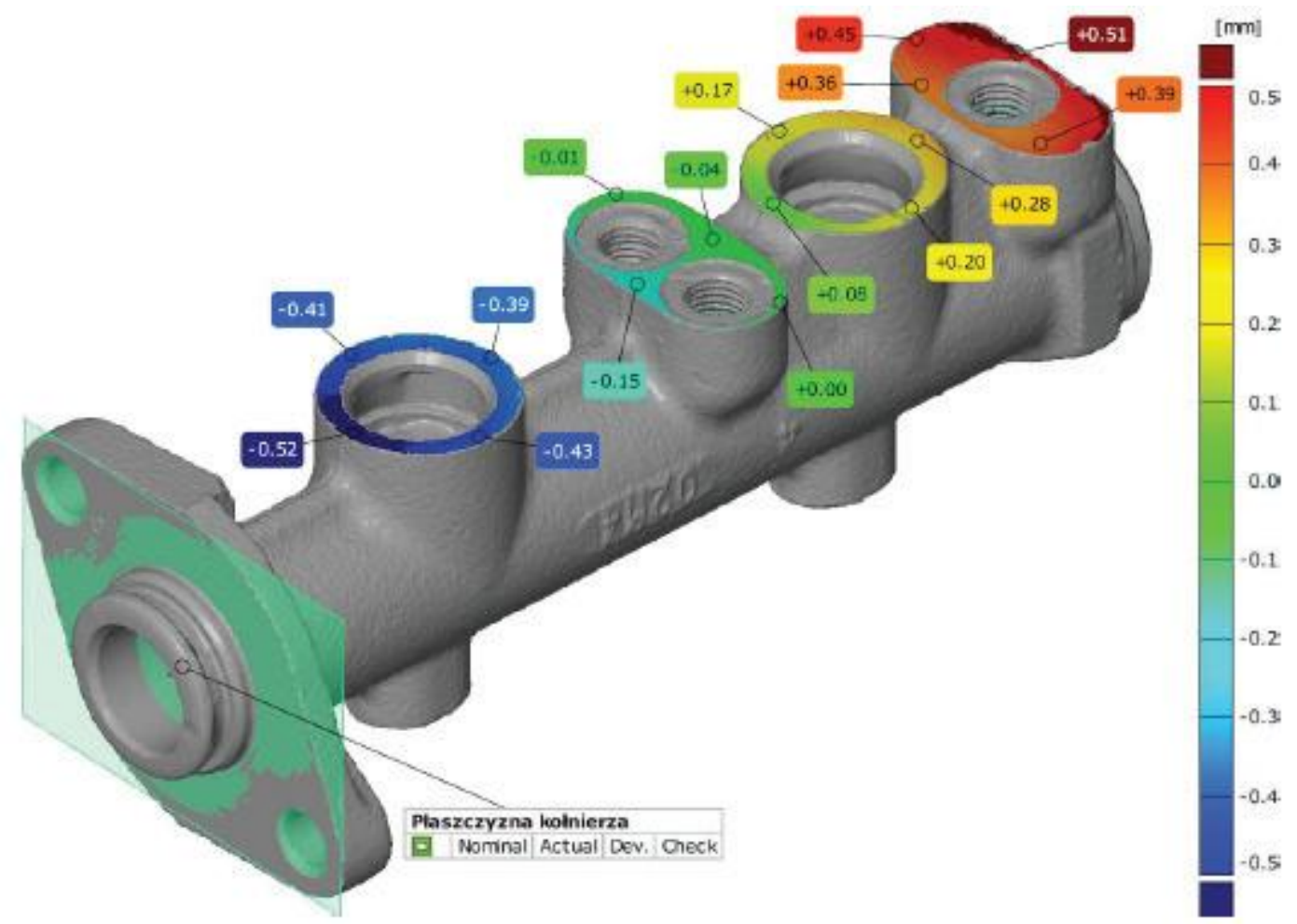

Fig. 12. Measurement results of deviations of the perpendicularity of the upper plane relative to the flange plane

\section{Summary}

The procedure indicates the high usefulness of 3D scanning in reverse engineering. In this method, unfortunately, there is no simple transition from the surface model to the CAD solid model, which of course excludes saving in *.stl format. This shows that the potential of this reverse engineering method is still unused.

The work was carried out with the use of devices and apparatus purchased under the Operational

Program Development of Eastern Poland 2007-2013, MOLAB Project entitled "Development of the research base of specialized laboratories of public universities in the Świętokrzyskie Region",

Operational Program Innovative Economy, priority axis 2: R\&D infrastructure, Measure 2.2, Support

for creation of joint research infrastructure of scientific units,

POIG 02.02.00-26-023/08-00 of May 19, 2009 


\section{REFERENCES}

[1] Wang J., Gu D., Yu Z., Tan Ch., Zhou L. "A framework for 3D model reconstruction in reverse engineering". Computers \& Industrial Engineering. 63, 4 (2012): 1189-1200, https://doi.org/10.1016/i.cie.2012.07.009.

[2] Barbero B.R., Ureta E.S. "Comparative study of different digitization techniques and their accuracy". ComputerAided Design. 43, 2 (2011): 188-206, https://doi.org/10.1016/j.cad.2010.11.005.

[3] Ameen W., Al-Ahmari A.M., Mian S.H. "Evaluation of handheld scanners for automotive applications". Applied Sciences. 8, 217 (2018), https://doi.org/10.3390/app8020217.

[4] Anwer N., Mathieu L. "From reverse engineering to shape engineering in mechanical design". CIRP Annals Manufacturing Technology. 65 (2016): 165-168, https://doi.org/10.13140/RG.2.2.14297.93281.

[5] Savio E., De Chiffre L., Schmitt R. "Metrology of freeform shaped parts". CIRP Annals - Manufacturing Technology. 56, 2 (2007): 810-835, https://doi.org/10.1016/i.cirp.2007.10.008.

[6] Zaborniak M., Tofil-Kozdra I. „Zastosowanie inżynierii odwrotnej w procesie odtwarzania kół zębatych”. Mechanik. 12 (2015): 193-196, https://doi.org/10.17814/mechanik.2015.12.586.

[7] Karczewski M. „Zastosowanie skanerów 3D w technice wojskowej”. Mechanik. 1 (2017): 52-53, https://doi.org/10.17814/mechanik.2017.1.8.

[8] Dúbravčík M., Kender Š. "Application of reverse engineering techniques in mechanics system services". Procedia Engineering. 48 (2012): 96-104, https://doi.org/10.1016/i.proeng.2012.09.491.

[9] Vagovský J., Buranský I., Görög A. "Evaluation of measuring capability of the optical 3D scanner". Procedia Engineering. 100 (2015): 1198-1206, https://doi.org/10.1016/i.proeng.2015.01.484.

[10] Gapinski B., Wieczorowski M., Marciniak-Podsadna L., Dybalab B., Ziolkowski G. "Comparison of different methods of measurement geometry using CMM, optical scanner and computed tomography 3D". Procedia Engineering. 69 (2014): 255-262, https://doi.org/10.1016/j.proeng.2014.02.230.

[11] GOM Opical Measuring Techniques, Germany (2012). Instrukcja obsługi skanera Atos II.

[12] Kumor S. „Projekt procesu technologicznego wybranego element klasy korpus z zastosowaniem inżynierii odwrotnej". Praca dyplomowa magisterska, wykonana pod kierunkiem dr. inż. Jerzego Bochni. Politechnika Świętokrzyska, Kielce, 2016. 